\title{
Determination of size fractions and concentrations of airborne particulate matter generated from construction and demolition waste processing facilities
}

\author{
Jason M. Young • Timothy M. Kelly • Leonard Vance
}

Received: 27 February 2008 / Accepted: 11 August 2008 / Published online: 24 September 2008

(C) The Author(s) 2008. This article is published with open access at Springerlink.com

\begin{abstract}
Construction and Demolition (C\&D) processing and recycling facilities accept waste materials that are generated during construction and demolition activities. The processing facility sorts, processes, and transfers the material to another operation. Active stationary particulate sampling devices were employed to quantify the particle sizes of interest. Results were compared to United States Environmental Protection Agency National Ambient Air Quality Standards (NAAQS) and United States Occupational Safety and Health Administration (OSHA) standards. Airborne particulate levels were found to be higher inside of buildings even when minimal activity is taking place. Interior road type seems to impact airborne particulate levels, and misting activities can significantly reduce the amount of airborne particulate matter exiting a building. The data indicate that $C \& D$ processing facilities may exceed current NAAQS at certain locations but do not exceed OSHA standards.
\end{abstract}

Keywords Air - Construction - Demolition - Dust - USEPA . OSHA $\cdot$ Particulate matter $\cdot$ Standards

J. M. Young $(\bowtie)$

Henrico County,

1590 E. Parham Road,

Richmond, VA 23273, USA

e-mail: jjchokie@comcast.net

T. M. Kelly

Joyce Engineering, Inc.,

1604 Ownby Lane,

Richmond, VA 23220, USA

L. Vance

Department of Epidemiology and Community Health,

Virginia Commonwealth University,

Richmond, VA 23284, USA

\section{Introduction}

Construction and Demolition (C\&D) debris consists of the materials generated during the construction, renovation, and demolition of buildings, roads, and bridges (USEPA 2007a). Construction and Demolition processing and recycling facilities accept waste materials such as concrete, wood, gypsum, asphalt, shingles, glass, and steel. Typical operations at these facilities include sorting, shredding, and grinding.

The use of C\&D processing facilities is a growing trend. However, a consequence of this process is the generation of particulate matter (PM). Particulate matter is a mixture of extremely small particles and liquid droplets in the air (USEPA 2006). Fine particles are less than $2.5 \mu \mathrm{m}$ in diameter $\left(\mathrm{PM}_{2.5}\right)$ and often result from fuel combustion (USEPA 2006). Coarse dust is between 2.5 and $10 \mu \mathrm{m}$ in diameter (USEPA 2006). Particulate matter 10 includes both fine and coarse dust particles and is generally emitted by sources (USEPA 2006). Potential sources of $\mathrm{PM}_{10}$ at C\&D processing facilities include sorting, grinding, and shredding operations, materials handling, unpaved roads, and windblown dust. The potential impacts to health, aesthetics, air quality, and manufacturing equipment as a result of the generation of airborne particulates from $C \& D$ processing facilities are unknown.

The particle sizes of interest in this study were $\mathrm{PM}_{10}$ and $\mathrm{PM}_{2.5}$. These were studied since $\mathrm{PM}_{10}$ and $\mathrm{PM}_{2.5}$ are the particulate sizes of interest regulated under the Clean Air Act. The Clean Air Act requires the United States Environmental Protection Agency (USEPA) to set National Ambient Air Quality Standards (NAAQS) for pollutants considered harmful to public health and environment. Primary standards set limits to protect public health, while secondary standards set limits to protect public welfare. As 
such, $\mathrm{PM}_{10}$ and $\mathrm{PM}_{2.5}$ have current ambient air quality standards promulgated by the United States Environmental Protection Agency (see Table 1). These standards are found in the Code of Federal Regulations 40CFR50.6 and 40CFR50.13 and on the EPA website (National Archives and Records Administration 2007; USEPA 2007b).

In addition to $\mathrm{PM}_{10}$ and $\mathrm{PM}_{2.5}$, inert or nuisance dust levels were also quantified according to United States Occupational Safety and Health Administration (OSHA) standards. These standards are for particulates that are not otherwise regulated by OSHA and consider total dust (National Institute of Occupational Safety and Health (NIOSH) 0500) and respirable fraction (NIOSH 0600) concentrations (see Table 2; United States Department of Labor 2006).

Total dust includes all airborne particles regardless of their size, while respirable dust refers to dust particles that are small enough to penetrate deep into the lungs (United States Department of Labor 2006). OSHA regulates exposure under the Code of Federal Regulations 29CFR1910.1000. These standards are found in the Code of Federal Regulations and on the OSHA website (National Archives and Records Administration 2007 and United States Department of Labor 2006). Under these regulations, allowable exposure is quantified as permissible exposure limits or time-weighted averages that are not to be exceeded for an 8-h workday within a 40-h workweek. These were of interest in order to better understand worker exposure levels and pathways.

Table 1 EPA NAAQS

\begin{tabular}{llll}
\hline Pollutant & $\begin{array}{l}\text { Primary } \\
\text { standards }\end{array}$ & $\begin{array}{l}\text { Averaging } \\
\text { times }\end{array}$ & $\begin{array}{l}\text { Secondary } \\
\text { standards }\end{array}$ \\
\hline $\begin{array}{c}\text { Particulate } \\
\text { matter }\left(\mathrm{PM}_{10}\right)\end{array}$ & Revoked $^{\mathrm{a}}$ & $\begin{array}{c}\text { Annual }^{\mathrm{a}} \\
\text { arith. mean })\end{array}$ & \\
$\begin{array}{c}\text { Particulate } \\
\text { matter }\left(\mathrm{PM}_{2.5}\right)\end{array}$ & $150 \mu \mathrm{g} / \mathrm{m}^{3}$ & $\begin{array}{c}24 \mathrm{~h}^{\mathrm{b}} \\
\text { Annual }^{\mathrm{c}} \\
\text { (arith. Mean })^{3}\end{array}$ & Same as primary \\
\hline
\end{tabular}

Units of measure for the standards are micrograms per cubic meter of air $\left(\mu \mathrm{g} / \mathrm{m}^{3}\right)$.

Footnotes:

${ }^{a}$ Due to a lack of evidence linking health problems to long-term exposure to coarse particle pollution, the agency revoked the annual $\mathrm{PM}_{10}$ standard in 2006 (effective December 17, 2006).

${ }^{\mathrm{b}}$ Not to be exceeded more than once per year on average over 3 years.

${ }^{\mathrm{c}}$ To attain this standard, the 3 -year average of the weighted annual mean $\mathrm{PM}_{2.5}$ concentrations from single or multiple communityoriented monitors must not exceed $15.0 \mu \mathrm{g} / \mathrm{m}^{3}$.

${ }^{d}$ To attain this standard, the 3-year average of the 98th percentile of 24-h concentrations at each population-oriented monitor within an area must not exceed $35 \mu \mathrm{g} / \mathrm{m}^{3}$ (effective December 17, 2006).
Table 2 OSHA standards

\begin{tabular}{lll}
\hline Substance & $\mathrm{ppm}^{\mathrm{a}, \mathrm{b}}$ & $\mathrm{mg} / \mathrm{m}^{3 \mathrm{a}, \mathrm{c}}$ \\
\hline Total dust & - & 15 \\
Respirable fraction & - & 5 \\
\hline
\end{tabular}

${ }^{\mathrm{a}}$ The permissible exposure limits are 8-h TWAs unless otherwise noted; a (C) designation denotes a ceiling limit. They are to be determined from breathing-zone air samples.

${ }^{\mathrm{b}}$ Parts of vapor or gas per million parts of contaminated air by volume at $25^{\circ} \mathrm{C}$ and 760 torr.

${ }^{\mathrm{c}}$ Milligrams of substance per cubic meter of air. When entry is in this column only, the value is exact; when listed with a ppm entry, it is approximate.

Three different C\&D processing facilities, located in the mid-Atlantic, the southeast, and the northeast United States were studied. Each of these facilities shared common features and had distinctive differences. The following sections detail the study and the sampling results. The information gathered during this study should be useful to C\&D processing facility owners, health professionals, communities, and environmental regulators in identifying possible impacts to health, aesthetics, air quality, and manufacturing equipment.

\section{Materials and methods}

This study employed active stationary particulate sampling devices to accurately quantify the size fractions and concentrations of particulate matter generated by the operation of C\&D processing facilities. Particulate monitors were located near facility boundaries as well as near potential sources of contamination, such as areas of processing operations or dusty roads, in order to capture the impact of such sources. The particle sizes of interest were those with diameters less than $10 \mu \mathrm{m}\left(\mathrm{PM}_{10}\right)$ and $2.5 \mu \mathrm{m}\left(\mathrm{PM}_{2.5}\right)$ and total and respirable dust levels.

For comparison with United States Environmental Protection Agency National Ambient Air Quality Standards (see Table 1), Partisol ${ }^{\circledR}$ FRM Model 2000 Air Samplers (Partisol ${ }^{\circledR}$ ) were used to sample for $\mathrm{PM}_{10}$ and $\mathrm{PM}_{2.5}$ (Thermo Scientific 2007). This equipment has an EPA reference method for both $\mathrm{PM}_{10}$ (RFPS-1298-126) and $\mathrm{PM}_{2.5}$ (RFPS-0498-117).

Because sampling only took place over a period of 2 weeks at each sampling location, results are not valid for the demonstration of compliance with NAAQS. Furthermore, NAAQS typically do not apply to indoor air quality whereas some of the results presented in this report were collected under roof. Sampling locations were also biased towards areas of high activity rather than near typical ambient locations. 


\section{Site descriptions}

\section{Site A}

The site, located in mid-Atlantic United States, receives a combination of municipal solid waste (MSW), C\&D material, cardboard, and mixed recyclables. There are no grinding or mulching operations at the facility. There is no misting system in place nor do they spray down the waste stream. The receiving area and all roads are paved.

The receiving building is indoors. The receiving building is covered and has openings on both ends for vehicles to enter and exit. Large amounts of concrete, metal, and cardboard are unloaded separately from the main waste stream, which allows the facility to more easily recycle these materials. The waste material is then pushed into piles by a dozer. An excavator then picks up the material from the debris piles and loads it into trucks, which take the material to a landfill.

Partisol ${ }^{\circledR}$ Units 1, 2, and 3 were placed along the perimeter of the site. Unit 4 was placed just outside of the receiving building and Unit 5 was placed inside the receiving building. Two Airlite ${ }^{\mathrm{TM}}$ air sampling devices were placed near Unit 5 inside the receiving building.

\section{Site B}

The site, located in the southeastern United States, receives a combination of C\&D material, concrete, and mixed recyclables. The facility also manufactures a cover product which is exported for use as an alternate daily cover (ADC). They bale cardboard and plastic onsite but do not have any grinding or mulching operations. They periodically use a sprinkler to spray the receiving area down with water but do not operate a misting system. The receiving area and all roads are paved.

Materials brought to the facility are unloaded outside. A dozer pushes the waste material into a pile. Materials that are recyclable are brought into a covered building by a dozer. Large amounts of recyclables may be unloaded directly in the covered building. This material is then pushed by a dozer through the building and picked up by an excavator and placed onto a screen. Occasionally, recyclable material is pushed directly to the pile that is placed onto the screen without going through the building. The screen allows anything smaller than two inches to fall through. This material is used as ADC. Material larger than two inches is taken to a conveyor belt. The conveyor belt brings the larger material to a picking room. The material is then hand sorted according to type of recyclable material. The recyclable material is then sent to various locations. Material that was not moved inside of the building is picked up with an excavator and loaded into trucks, which take the material to a landfill.

Partisol ${ }^{\circledR}$ Unit 1 was placed inside the receiving building and Unit 2 was placed just outside of the receiving building. Units 3, 4, and 5 were placed along the perimeter of the site. Two Airlite ${ }^{\mathrm{TM}}$ air sampling devices were placed near Unit 1 inside the receiving building.

\section{Site C}

The site, located in northeastern United States, receives a combination of C\&D material, MSW, concrete, wood products, cardboard, metal, gypsum, and sheetrock. The facility also manufactures a cover product, which is exported to landfills for use as an ADC. They have a mulching operation where wood products are ground onsite and converted to mulch as well as a cardboard baling operation. They operate a misting system in the indoor receiving area and periodically use a hose to spray water on the tipped material. The receiving area and majority of roads are paved. There are a few gravel and dirt roads.

The receiving area is indoors. Materials brought to the facility are unloaded in the receiving building. The building is covered and has two openings on one side. Vehicles enter and exit through one of the openings. ADC material is removed by trucks from the other opening. A dozer pushes the tipped material into a pile. This material is then picked up by an excavator and placed onto a conveyor belt. The conveyor belt brings the material to a picking room. The material is then hand sorted according to the type of recyclable material. The recyclable material is then exported to various locations. Smaller pieces of material and fines that are not sorted as recyclable are placed through a grinder and dropped onto a concrete floor by a conveyor belt to be exported as ADC.

Partisol ${ }^{\circledR}$ Units 1, 4, and 5 were placed along the perimeter of the site. Unit 2 was placed inside the receiving building and Unit 3 was placed just outside of the receiving building. Two Airlite ${ }^{\mathrm{TM}}$ air sampling devices were placed near Unit 2 inside the receiving building.

\section{Sampling protocol}

Five Partisol ${ }^{\circledR}$ air sampling devices were employed at each of the three sampling sites. The devices were calibrated prior to sampling. Attempts were made to place the devices in similar types of locations at each site in order to obtain representative and comparative measurements. One unit was positioned under roof, typically in the tipping area. The tipping area is a location on the floor where the material from the trucks is deposited. Tipping floor activities consisted of depositing the C\&D waste onto the floor of 
the building and sorting, separating and removing the waste for recycling.

Another device was stationed outside and directly opposite of the under roof unit in order to access the effectiveness of the building's ability to reduce dust. The three other units were positioned at various locations along each facility's perimeter to quantify particulates at property boundaries. An EPA designed $\mathrm{PM}_{2.5}$ WINS Impactor sampling device was used with the Partisol ${ }^{\circledR}$ air sampling units when collecting $\mathrm{PM}_{2.5}$ data.

Preweighed $47-\mathrm{mm}$ Teflon ${ }^{\circledR}$ filters with a $2.0-\mu \mathrm{m}$ pore size were used with the Partisol ${ }^{\circledR}$ air sampling devices to collect airborne particulate matter. Filters were inspected for imperfections and loaded into clean filter cassettes in a clean room environment prior to deployment into the field. Each Partisol ${ }^{\circledR}$ device was programmed to sample for 24 consecutive hours at a rate of $16.7 \mathrm{l} / \mathrm{min}$. Immediately prior to the start of the sampling period, the filter cassette was loaded into each sampling device. At the end of each sampling period, the filter cassette was collected and placed into a sealed metal carrying case. The filter was later removed from the filter cassette in a clean room environment and placed into its respective Petri dish for transport.

The status of each Partisol ${ }^{\circledR}$ unit was accessed periodically throughout the day and at the conclusion of each 24-h sampling period. Various parameters were accessed in order to ensure that an accurate sample was collected. These parameters include but are not limited to: total sample time, average flow, ambient temperature, average pressure, and status codes.

NIOSH analytical methods for total nuisance dust and respirable fraction nuisance dust levels were used for comparison with the United States Occupational Safety and Health Administration standards (see Table 2). SKC Airlite ${ }^{\mathrm{TM}}$ Model 110-100 air samplers (Airlite ${ }^{\mathrm{TM}}$ ) were used to measure total nuisance dust (NIOSH 0500) and respirable fraction nuisance dust (NIOSH 0600) levels (SKC Gulf Coast Incorporated 2006).

Because these units were not placed directly on workers, the results are not valid for the demonstration of compliance with OSHA standards. However, the equipment was placed in areas where personnel typically worked. Two Airlite $^{\mathrm{TM}}$ air sampling devices were employed at each of the three sampling locations. The devices were calibrated prior to sampling. Both units were positioned under roof, typically in the receiving building near the Partisol ${ }^{\circledR}$ device that was placed under roof. Both Airlite ${ }^{\mathrm{TM}}$ units were placed about $4 \mathrm{ft}$ from one another, and the sample inlets were located approximately $5 \mathrm{ft}$ above ground level (in the typical breathing zone). An aluminum cyclone was used to restrict the particle size $(3.5-\mu \mathrm{m} 50 \%$ cut-point at $2.8 \mathrm{l} / \mathrm{min})$ collected for the respirable dust samples.
Preweighed polyvinyl chloride filters with a $5-\mu \mathrm{m}$ pore size were used with the Airlite ${ }^{\mathrm{TM}}$ air sampling devices to collect total and respirable dust measurements. Each device was manually started at the beginning of the workday and manually stopped after $8 \mathrm{~h}$ of sampling. Total nuisance dust was sampled at a rate of $2.0 \mathrm{l} / \mathrm{m}$, and respirable nuisance dust was sampled at a rate of $2.5 \mathrm{1} / \mathrm{m}$. Immediately prior to the start of the sampling period, a filter was installed in the sampling device to collect the dust. All filters were inspected for imperfections. At the end of each sampling period, the filters were collected and placed into a plastic bag for transport. The status of each Airlite ${ }^{\mathrm{TM}}$ air sampling device was accessed periodically and at the conclusion of each 8-h sampling period.

A trip blank was collected for each type of sample during each sampling event to help ensure proper sampling procedures. The samples were then shipped, under chainof-custody control, to a certified laboratory for analysis using gravimetric testing techniques. Each filter was weighed by the laboratory before and after sample collection to determine the net gain due to the particulate matter. Time-weighted average results were calculated using volume data. The laboratory level of quantitation for $\mathrm{PM}_{10}$ and $\mathrm{PM}_{2.5}$ measurements was $0.1 \mathrm{mg}$. The laboratory level of quantitation for total and respirable dust measurements was $0.05 \mathrm{mg}$. There were no quantified detections in the trip blanks during the study.

Each of the three sampling locations was sampled during two different time periods. The sampling events were staggered in order to collect data during different periods of operation. $\mathrm{PM}_{2.5}$ data were collected during the first two sample days during each sampling period. $\mathrm{PM}_{10}$ data were collected during the last two sample days during each sampling period. Total and respirable dust level samples were collected each of the four days of each sampling period.

Information on variables that may have possibly influenced the sample results was collected. Records indicating the types and quantities of materials entering and exiting the facilities were obtained from each facility during each sampling period. Daily weather measurements including average wind direction and speed, temperature, humidity, total precipitation, and barometric pressure were collected. The total distance of each sampling unit from various points of interest (i.e., tipping area, roadways, etc.) was also measured.

\section{Statistical methods}

The data collected were entered into Statistical Analysis Software (SAS) version 8.2 (SAS 2001). SAS software was used for all statistical analyses and a 5\% significance level was used for all tests. Analysis of variance (ANOVA) tests 
were used to compare data. Normality of the data was checked prior to running the ANOVAs to compare all of the units at each site.

All of the data were normal except for the $\mathrm{PM}_{10}$ data of Unit 4 at Site $\mathrm{B}$, which had a Shapiro Wilk $p$ value of $<0.0001$ and the $\mathrm{PM}_{10}$ data of Unit 4 at Site $C$, which had a Shapiro Wilk $p$ value of 0.0043 . Due to an equipment malfunction, the $\mathrm{PM}_{10}$ data of Unit 4 at Site $\mathrm{B}$ only contained three samples, which made it difficult to achieve normality. One data point from the $\mathrm{PM}_{10}$ data of Unit 4 at Site $\mathrm{C}$ was significantly higher than the other three data points; however, neither the laboratory nor the field notes indicated any problems with the data.

In cases when the laboratory did not report a quantified detection, half of the quantitation limit was used for analysis.

Each site was studied individually to determine statistical significance of various fields of interest. At each site, the $\mathrm{PM}_{10}$ and $\mathrm{PM}_{2.5}$ data collected from the five Partisol ${ }^{\circledR}$ air sampling devices were compared to determine if a significant difference existed between the measurements collected in the units. Multiple comparison tests were run to determine which means were different. Tukey's studentized range test was used to identify which means were significantly different in these cases. Duncan's multiple range test was also used in one case.

The sites were also compared to one another in order to determine statistical significance of various fields of interest. If a statistically significant difference appeared to exist, then multiple comparison tests were run to determine which means were different. Tukey's studentized range test was used to identify which means were significantly different in these cases.

\section{Results}

\section{Site A results}

The averages of the $\mathrm{PM}_{10}$ data between the five sampling units were not statistically significantly different at $\alpha=.05$ $(p=0.1488)$; however, the averages of the $\mathrm{PM}_{2.5}$ data between the five sampling events were marginally significantly different $(p=0.0475)$. Tukey's studentized range test did not show any significant differences in the $\mathrm{PM}_{2.5}$ data; however, Duncan's test showed a significant difference between Unit 5 and the rest of the units. Even though these results may not be statistically significantly different, the results may be practically significantly different.

The greatest concentrations of $\mathrm{PM}_{10}$ and $\mathrm{PM}_{2.5}$ were measured in the receiving building by Unit 5 . Unit 4 , which was placed $50 \mathrm{ft}$ from the building's entrance or exit, generally recorded the second greatest concentrations of
$\mathrm{PM}_{10}$ and $\mathrm{PM}_{2.5}$. See Fig. 1 for graphical results of $\mathrm{PM}_{10}$ data and Fig. 2 for graphical results of $\mathrm{PM}_{2.5}$ data.

The $\mathrm{PM}_{10}$ measurements exhibited a slight positive linear trend to the volume of inbound and outbound material. The volume of inbound material refers to the amount of C\&D waste deposited on the tipping floor and outbound material is the sorted waste that is moved out of the buildings onto trucks. Unit 5, in particular, displayed a positive linear trend. However, there was not a clear linear trend between the $\mathrm{PM}_{2.5}$ measurements and the volume of material. Although concentrations of $\mathrm{PM}_{10}$ and $\mathrm{PM}_{2.5}$ dust levels varied considerably between sample events, the relationship of the measurements between each unit remained similar.

If these results were valid for determination of compliance with NAAQS, then several possible exceedances occurred. When these results were compared to EPA $\mathrm{PM}_{10}$ NAAQS, Unit 5 exceeded the 24-h standard of $150 \mu \mathrm{g} / \mathrm{m}^{3}$ during sampling events 1 and 2 . Unit 4 exceeded the standard during sampling event 1 . When these results were compared to EPA $\mathrm{PM}_{2.5}$ NAAQS, Unit 5 exceeded the 24-h standard of $35 \mu \mathrm{g} / \mathrm{m}^{3}$ during sampling events 1 and 2 collected inside of the receiving building.

If these results were valid for determination of compliance with OSHA standards, then neither the total nor respirable dust level measurements would have exceeded OSHA total or respirable dust level standards (see Figs. 3 and 4; note: the total dust value collected during the second sampling event at Site A was excluded from analysis because loose particles present inside of the cassette were included in the laboratory analysis). Both total and respirable dust measurements exhibited a positive linear trend to the volume of inbound and outbound material.

\section{Site B results}

The averages of the $\mathrm{PM}_{10}$ data between the five sampling units were significantly different at $\alpha=.05 \quad(p=0.0002)$; however, the average of the $\mathrm{PM}_{2.5}$ data between the five sampling units were not significantly different $(p=0.3927)$.

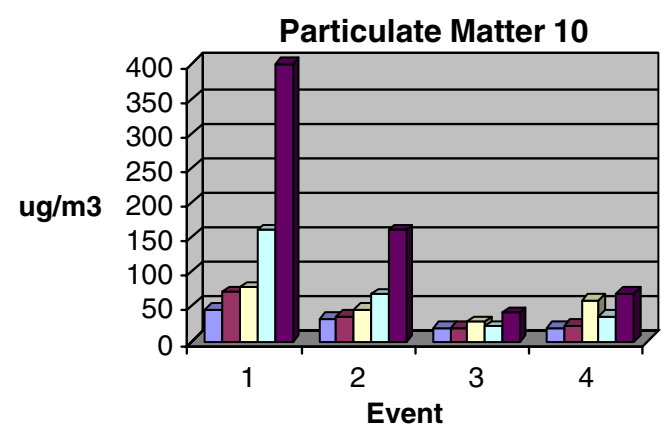

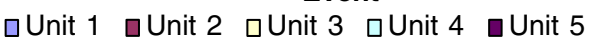

Fig. 1 Site $\mathrm{A} \mathrm{PM}_{10}$ 


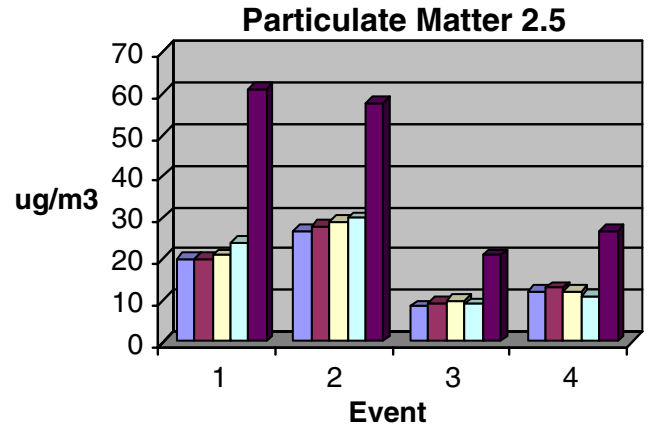

口Unit 1 aUnit $2 \quad$ 口Unit $3 \quad$ aUnit $4 \quad$ aUnit 5

Fig. 2 Site $\mathrm{A} \mathrm{PM}_{2.5}$

The greatest concentrations of $\mathrm{PM}_{10}$ were measured just outside of the entrance to the material holding building by Unit 2. Unit 1, located inside of the building, measured the second greatest concentrations of $\mathrm{PM}_{10}$. Units 3 and 4 typically measured concentrations of $\mathrm{PM}_{10}$ less than the measurements sampled in Units 1 and 2. Unit 5 measured the lowest concentrations of $\mathrm{PM}_{10} \cdot \mathrm{PM}_{10}$ concentrations in Units 1 and 2 were significantly different from Unit 5 . The greatest concentrations of $\mathrm{PM}_{2.5}$ were measured closest to the sorting and ADC operations by Unit 3. Units 1 and 2 typically measured $\mathrm{PM}_{2.5}$ concentrations less than that measured in Unit 3. Units 4 and 5 measured the lowest concentrations of $\mathrm{PM}_{2.5}$. See Fig. 5 for graphical results of $\mathrm{PM}_{10}$ data and Fig. 6 for graphical results of $\mathrm{PM}_{2.5}$ data (note: the $\mathrm{PM}_{10}$ sample from Unit 4 during the first sampling event and the $\mathrm{PM}_{2.5}$ sample from Unit 4 during the fourth sampling event were not submitted to the laboratory due to equipment malfunctions).

Neither the $\mathrm{PM}_{10}$ nor the $\mathrm{PM}_{2.5}$ measurements exhibited a strong linear trend to the volume of inbound and outbound material with the exception of Unit 1. Unit 1 displayed a slight positive linear trend. The relationship of the measurements between each Unit varied with both $\mathrm{PM}_{10}$ and $\mathrm{PM}_{2.5}$ measurements.

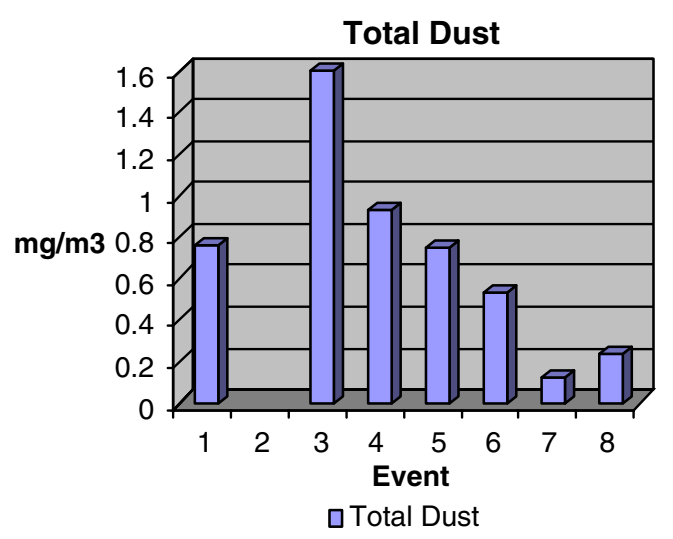

Fig. 3 Site A total dust

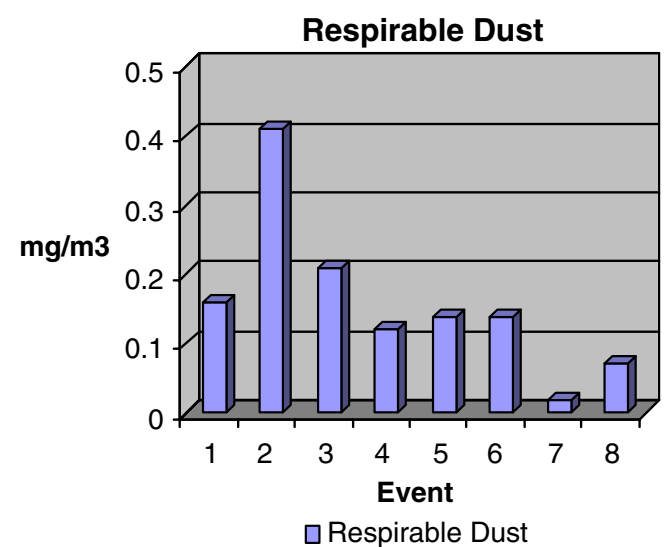

Fig. 4 Site A respirable dust

If these results were valid for determination of compliance with NAAQS, then several possible exceedances occurred. When these results were compared to EPA $\mathrm{PM}_{10}$ NAAQS, Units 1 and 2 exceeded the 24-h standard of $150 \mu \mathrm{g} / \mathrm{m}^{3}$ during each sampling event and Unit 3 exceeded the standard during sampling event 3 . When these results were compared to EPA $\mathrm{PM}_{2.5}$ NAAQS, Unit 2 exceeded the 24-h standard of $35 \mu \mathrm{g} / \mathrm{m}^{3}$ during sampling event 3 and Unit 3 exceeded the standard during sampling events 1 and 4 .

If these results were valid for determination of compliance with OSHA standards, then neither the total nor respirable dust level measurements would have exceeded OSHA total or respirable dust level standards (see Figs. 7 and 8; note: the respirable dust sample from the fourth sampling event was not submitted to the laboratory due to an equipment malfunction). Neither total dust nor respirable fraction measurements exhibited a positive linear trend to the volume of inbound and outbound material.

\section{Site $\mathrm{C}$ results}

The averages of the $\mathrm{PM}_{10}$ and $\mathrm{PM}_{2.5}$ data between the five sampling units were significantly different $(p<0.0001)$. The

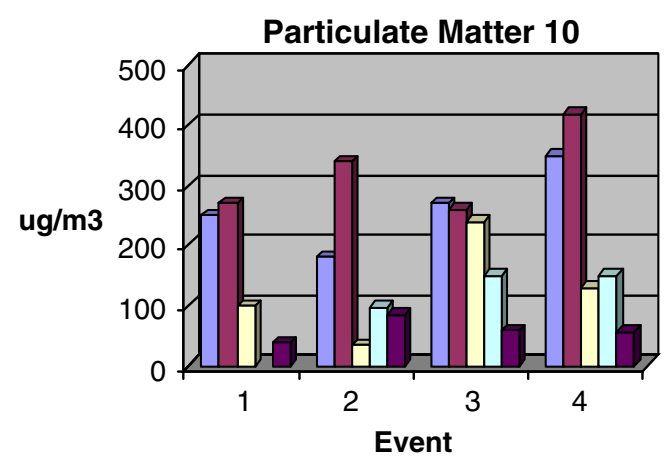

口Unit 1 aUnit 2 aUnit 3 aUnit 4 aUnit 5

Fig. 5 Site $\mathrm{B} \mathrm{PM}_{10}$ 


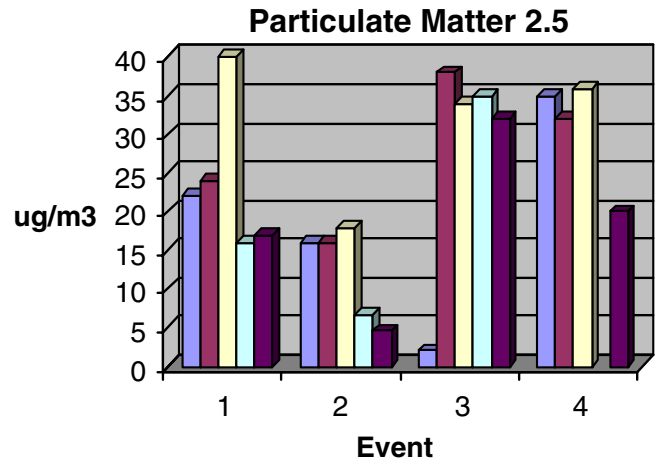

aUnit 1 aUnit $2 \quad$ aUnit 3 aUnit 4 aUnit 5

Fig. 6 Site $\mathrm{B} \mathrm{PM}_{2.5}$

greatest concentrations of $\mathrm{PM}_{10}$ were measured inside of the receiving building by Unit 2 .

The second greatest concentrations of $\mathrm{PM}_{10}$ were typically measured by Unit 5 along the southwest perimeter; however, the difference between the concentrations in Unit 2 and Unit 5 was very significant. Unit 3, located just outside of the receiving building, typically measured the third greatest concentrations of $\mathrm{PM}_{10}$. Units 1 and 4 measured similar concentrations of $\mathrm{PM}_{10}$. Unit 2 also measured the greatest concentrations of $\mathrm{PM}_{2.5}$. Unit 3 measured the second greatest concentrations of $\mathrm{PM}_{2.5}$; however, the difference between the concentration of $\mathrm{PM}_{2.5}$ in Unit 2 and 3 was significant. The other three units measured similar concentrations of $\mathrm{PM}_{2.5}$. See Fig. 9 for graphical results of $\mathrm{PM}_{10}$ data and Fig. 10 for graphical results of $\mathrm{PM}_{2.5}$ data.

Neither the $\mathrm{PM}_{10}$ nor the $\mathrm{PM}_{2.5}$ measurements exhibited a strong linear trend to the volume of inbound and outbound material with the exception of Unit 2. Unit 2 displayed a slight positive linear trend. Although concen-

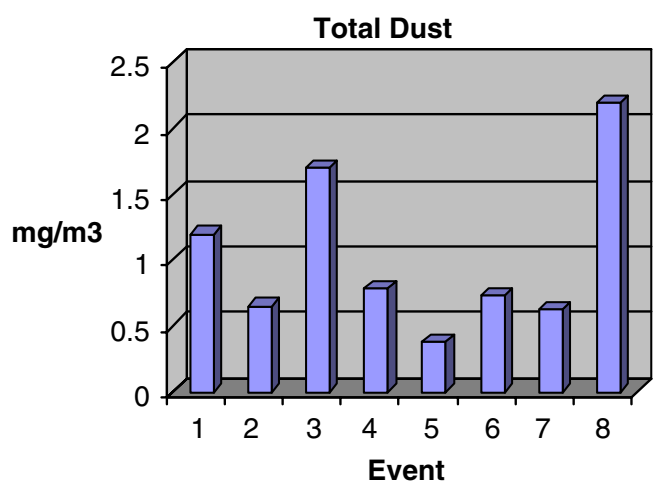

口Total Dust

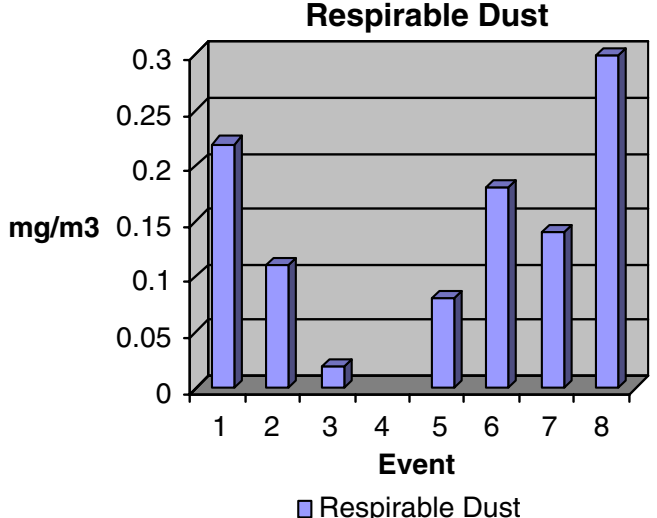

Fig. 8 Site B respirable dust

trations of $\mathrm{PM}_{10}$ and $\mathrm{PM}_{2.5}$ dust levels varied between sampling events, the relationship of the measurements between each Unit remained relatively constant.

If these results were valid for determination of NAAQS compliance, then several possible exceedances occurred. When these results were compared to EPA PM $\mathrm{PM}_{10}$ NAAQS, Unit 2 exceeded the 24-h standard of $150 \mu \mathrm{g} / \mathrm{m}^{3}$ during each sampling event. Unit 3 exceeded the standard during sampling event 3 and Unit 5 exceeded the standard during sampling events 1 and 2 . When these results were compared to EPA $\mathrm{PM}_{2.5}$ NAAQS, Unit 2 exceeded the 24-h standard of $35 \mu \mathrm{g} / \mathrm{m}^{3}$ during each sampling event and Unit 3 exceeded the standard during sampling events 1 and 2 .

If these results were valid for determination of compliance with OSHA standards, then neither the total nor respirable dust level measurements would have exceeded OSHA total or respirable dust level standards (see Figs. 11 and 12). Total and respirable dust measurements exhibited a slight positive linear trend to the volume of inbound and outbound material.

Fig. 7 Site B total dust

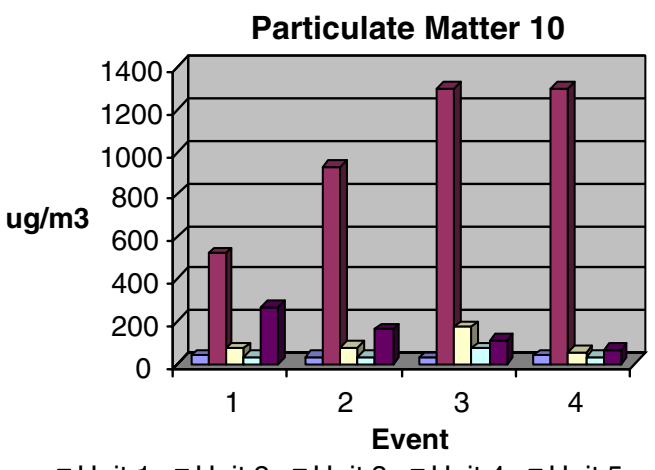

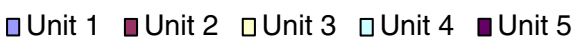

Fig. 9 Site $\mathrm{C} \mathrm{PM}_{10}$ 


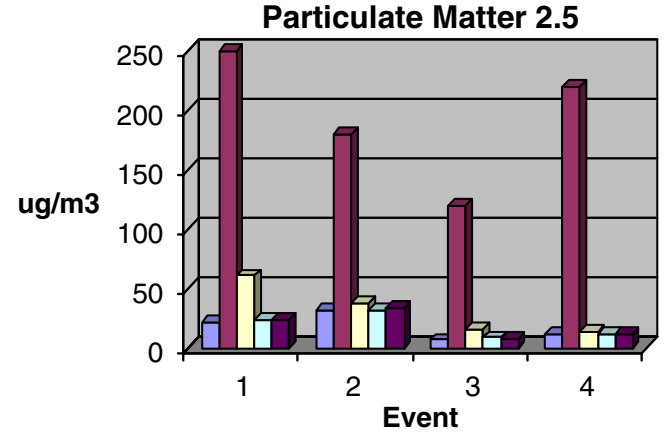

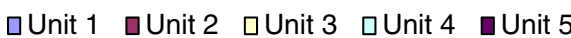

Fig. 10 Site $C \mathrm{PM}_{2.5}$

\section{Discussion}

It is difficult to compare the three facilities that were studied in this report. Although each facility processes construction and demolition debris, numerous operational differences exist. Different classifications of material also made it difficult to compare the possible impacts of the various types of materials being brought to and leaving the facilities.

In addition to these differences, it was also difficult to sample each facility in the same manner. For instance, the Partisol ${ }^{\circledR}$ and Airlite ${ }^{\mathrm{TM}}$ units that were placed under roof were located at different distances from the tipping area. It was not possible to locate the units at the same distances due to building designs and operational differences. The units that were located outside also had to be placed at various distances from roads and points of interest due to facility operation considerations.

Each C\&D processing facility will have its own circumstances to consider when considering measures to reduce airborne particulate levels (United States Department of Labor 2006). Operational differences, site layout, and building designs will all impact dust level concentrations.
However, the data collected from this study combined with general observations lead to several possible methods of reducing airborne particulate levels.

According to OSHA, employee exposure to dust can be reduced in one of three ways: prevention, control systems, or dilution and isolation. These broad concepts can be expanded to include the general reduction of airborne particulates across an entire site. Entry and exit doors should be made as small as possible in order to reduce dust migrating out of receiving buildings. A building's opening should not face a prevailing wind so that wind cannot sweep through the building and stir up dust. Dust curtains can be installed in areas where airborne particulates are generated to block the dust from migrating to more sensitive locations. Other dust suppression methods such as screens and covers could also be used to prevent dust from migrating (United States Department of Labor 2006). A water truck could be used to continuously wet paved or unpaved roads in areas where high amounts of airborne particulates are observed. Trucks could go through a wash area that would saturate their load prior to tipping.

After preventive measures are considered, control systems should be used to reduce remaining dust concentrations (United States Department of Labor 2006). Dust collection could be achieved inside of a receiving building by using a ventilation system. Wet dust suppression systems could also be used to capture airborne particulates. Such a system could be used to spray water onto material that is being dropped by a conveyor for example. An airborne dust capture system involving spraying a water mist over an entire area to capture the dust and causing it to settle is another alternative

Exposure may be unavoidable so if it is necessary for workers to be in an area where high levels of particulate matter is likely to be encountered, then workers may need to be equipped with dust masks or respirators. Mechanized

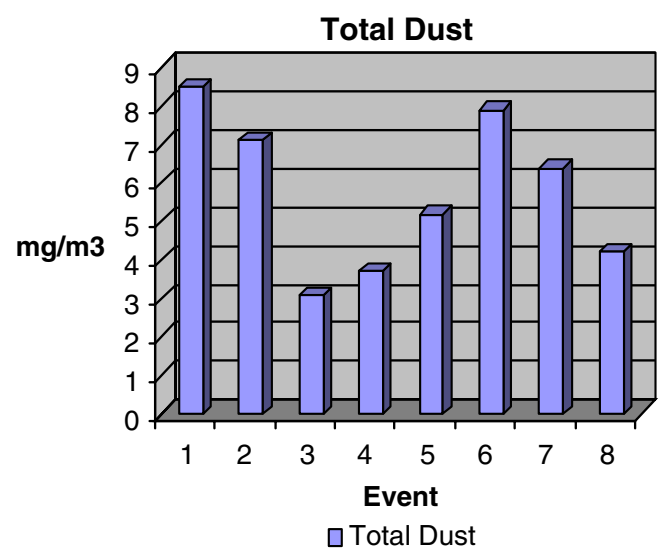

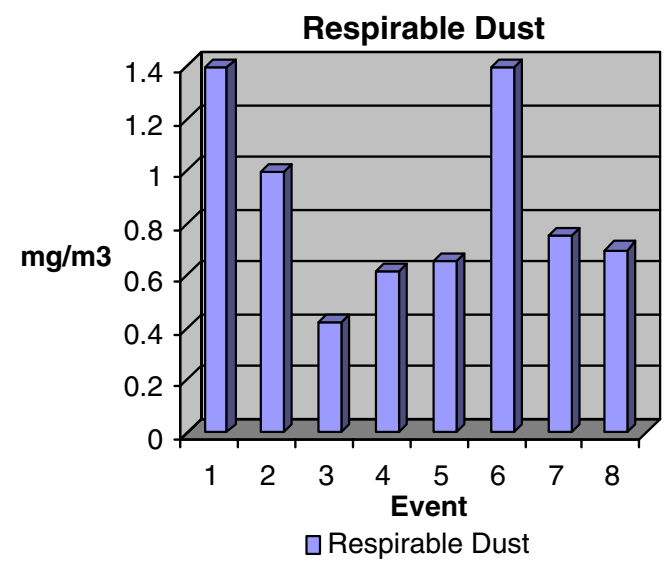

Fig. 12 Site $\mathrm{C}$ respirable dust

Fig. 11 Site C total dust 
equipment such as dozers should be airtight and equipped with air conditioners to help protect the operators. Protocols should be in place to deal with dust suppression and monitoring and workers should be educated regarding the importance of adhering to their company's protocols. A company should also have a preventive maintenance program for all dust control systems.

$\mathrm{PM}_{10}$ and $\mathrm{PM}_{2.5}$ concentrations recorded inside of the receiving building at Site $\mathrm{C}$ were significantly higher than concentrations measured at Sites A and B ( $p=0.0013$ and $p=0.0001)$. Total and respirable dust level concentrations recorded inside of the receiving building at Site $\mathrm{C}$ were also significantly higher than concentrations measured at Sites A and $\mathrm{B}(p<.0001)$. However, the Partisol ${ }^{\circledR}$ and Airlite ${ }^{\mathrm{TM}}$ units were located closer to the tipping area at Site $\mathrm{C}$ and tipping did not occur under roof at Site B.

As expected, airborne particulate levels tend to be higher inside of buildings even when minimal activity is taking place. This was evident by the relatively high $\mathrm{PM}_{10}$ and $\mathrm{PM}_{2.5}$ concentrations inside of the material storage building at Site B. If the results were valid for determination of NAAQS, then each of the three facilities would have exceeded the 24-h EPA PM 10 NAAQS at least one time in the sampling unit located inside of the building. However, despite the frequency of NAAQS exceedances, there were no OSHA total or respirable dust level exceedances inside of the buildings.

Also, as expected, airborne particulate levels tend to decrease as the distance between operational activity and the sampling devices increase. Concentrations of airborne particulate matter are higher in areas of high activity. Equipment usage, tipping, sorting, and baling all appeared to increase airborne particulate levels.

Road type also seemed to impact airborne particulate levels. $\mathrm{PM}_{10}$ levels in Partisol units located next to roads were lower when the road was paved compared to gravel. Unit 3 at Site A was located approximately $5 \mathrm{ft}$ away from a frequently used paved road and Unit 5 at Site $\mathrm{C}$ was located approximately $15 \mathrm{ft}$ away from a frequently used gravel road. Even though the difference in $\mathrm{PM}_{10}$ concentrations was not significant at $\alpha=.05(p=0.0732)$ a noticeable difference exists. The mean $\mathrm{PM}_{10}$ concentration of Unit 3 at Site $\mathrm{A}$ was 52.25, whereas the mean $\mathrm{PM}_{10}$ concentration of Unit 5 at Site $\mathrm{C}$ was 151.00 . However, $\mathrm{PM}_{2.5}$ levels were not much different between paved and dirt or gravel roads $(p=0.9109)$. The mean $\mathrm{PM}_{2.5}$ concentration of Unit 3 at Site A was 17.95 whereas the mean $\mathrm{PM}_{2.5}$ concentration of Unit 5 at Site $\mathrm{C}$ was 18.83 . The particulates from the gravel road may have been larger in size and may help explain the discrepancy between the particle sizes collected. However, due to confounding variables between the sites, the results may be attributed to something other than the difference in road type.
A misting system seems to significantly reduce the amount of airborne particulate matter exiting a building. The difference between $\mathrm{PM}_{10}$ and $\mathrm{PM}_{2.5}$ measurements inside the receiving building at Site $\mathrm{C}$ and just outside of the receiving building was very significant at $\alpha=.05$ ( $p=0.0027$ and $p=0.0018$, respectively). The difference between $\mathrm{PM}_{10}$ and $\mathrm{PM}_{2.5}$ measurements inside the receiving building in Site $\mathrm{A}$ and just outside of the receiving building was not significant at $\alpha=.05 \quad(p=0.3114$ and $p=0.0902$, respectively). These $p$-value results agree with the previous multiple comparison analyses performed for each individual site. However, these differences may also be attributed to differences in sampling locations (i.e., the distance between the indoor and outdoor sampling device, proximity to the building's opening, etc.) or to differences in building design (i.e., larger openings, position related to wind direction, etc.). Because Site B does not receive debris under roof, it cannot be directly compared to the other two; however, the difference between $\mathrm{PM}_{10}$ and $\mathrm{PM}_{2.5}$ measurements inside the material holding building and just outside of the building was not significant at $\alpha=.05$ ( $p=0.2835$ and $p=0.3439$, respectively).

\section{Conclusions and recommendations}

During this study, $\mathrm{PM}_{10}$ and $\mathrm{PM}_{2.5}$ concentrations recorded inside of the receiving building at Site $\mathrm{C}$ were significantly higher than concentrations measured at Sites A and B. Total and respirable dust level concentrations recorded inside of the receiving building at Site $\mathrm{C}$ were also significantly higher than concentrations measured at Sites A and B. As expected, airborne particulate levels tend to be higher inside of buildings even when minimal activity is taking place. However, despite the frequency of NAAQS exceedances, there were no OSHA total or respirable dust level exceedances inside of the buildings. Also, as expected, airborne particulate levels tended to decrease as the distance between operational activity and the sampling devices increased and road usage also seemed to impact airborne particulate levels. Misting seemed to significantly reduce the amount of airborne particulate matter exiting a building. However, this could be attributed to differences in sampling locations (i.e., the distance between the indoor and outdoor sampling device, proximity to the building's opening, etc.) or to differences in building design (i.e., larger openings, position related to wind direction, etc.).

There were numerous variables that may have impacted results for this study and these variables would need to be accounted for when planning future studies. This study has hopefully laid the foundation for additional airborne particulate matter studies at $C \& D$ processing facilities. Future studies aimed at determining airborne particulate levels 
should take into account the sampling unit's proximity to operations and other possible sources of airborne particulates.

Acknowledgements This research would not have been possible without the generous grant provided by the Environmental Research and Education Foundation. Leonard "Butch" Joyce of Joyce Engineering, Inc. deserves credit for having the insight to identify this research as necessary and valuable to the waste processing industry. Thesis committee members Dr. Leonard Vance, Dr. Peter deFur, and Dr. James Mays from Virginia Commonwealth University and Dr. Timothy Kelly from Joyce Engineering, Inc. provided instrumental support and advice throughout the study.

Open Access This article is distributed under the terms of the Creative Commons Attribution Noncommercial License which permits any noncommercial use, distribution, and reproduction in any medium, provided the original author(s) and source are credited.

\section{References}

National Archives and Records Administration. (2007). http://www. gpoaccess.gov/cfr/ about.html. Cited February 2007

SAS. (2001). version 8.2. Cary, North Carolina, United States

SKC Gulf Coast Incorporated. (2006). http://www.skcgulfcoast.com/ products/Featured Products.asp ?Cat $\mathrm{No}=110-100$. Cited October 2006

Thermo Scientific. (2007). http://www.thermo.com/com/cda/product/ detail/1,1055,1012 2674,00.html. Cited October 2006

United States Department of Labor. (2006). www.OSHA.gov. Cited December 2006

United States Environmental Protection Agency (USEPA). (2006). http://www.epa.gov/ oecaagct/trur.html. Cited December 2006

USEPA. (2007a). http://www.epa.gov/epaoswer/non-hw/debris-new/ index.htm. Cited January 2007

USEPA. (2007b). http://www.epa.gov/air/particlepollution/standards. html. Cited February 2007 